NBER WORKING PAPER SERIES

\title{
ESTIMATION OF CAUSAL EFFECTS IN EXPERIMENTS WITH MULTIPLE SOURCES OF NONCOMPLIANCE
}

\author{
John Engberg \\ Dennis Epple \\ Jason Imbrogno \\ Holger Sieg \\ Ron Zimmer \\ Working Paper 14842 \\ http://www.nber.org/papers/w14842
}

\author{
NATIONAL BUREAU OF ECONOMIC RESEARCH \\ 1050 Massachusetts Avenue \\ Cambridge, MA 02138 \\ April 2009
}

John Engberg is a research scientist at the RAND Corporation, Pittsburgh, PA 15213. Dennis Epple is the Thomas Lord Professor of Economics, Holger Sieg is the Friends of Allan Meltzer Professor in Economics, Jason Imbrogno is a Ph.D. student at Carnegie Mellon University, Tepper School of Business, Pittsburgh, PA 15213. Ron Zimmer is an Associate Professor at Michigan State University, College of Education, East Lansing, MI 48824. We would like to thank Stefan Holderlein, Guido Imbens, Blaise Melly, Robert Moÿtt, Chris Taber, Ken Wolpin, Tiemen Woutersen, and seminar participants at UT Austin, Brown University, Carnegie Mellon University, the University of Georgia, Johns Hopkins University, the University of Maryland, the University of Wisconsin-Madison, and the 5th Conference of German Economists Abroad at the University of Bonn for comments. We would also like to thank the "mid-sized urban school district" for sharing their data. Financial support for this research is provided by the Institute of Education Sciences (IESR305A070117 and R305D090016). The views expressed herein are those of the author(s) and do not necessarily reflect the views of the National Bureau of Economic Research.

NBER working papers are circulated for discussion and comment purposes. They have not been peerreviewed or been subject to the review by the NBER Board of Directors that accompanies official NBER publications.

(C) 2009 by John Engberg, Dennis Epple, Jason Imbrogno, Holger Sieg, and Ron Zimmer. All rights reserved. Short sections of text, not to exceed two paragraphs, may be quoted without explicit permission provided that full credit, including $\odot$ notice, is given to the source. 
Estimation of Causal Effects in Experiments with Multiple Sources of Noncompliance

John Engberg, Dennis Epple, Jason Imbrogno, Holger Sieg, and Ron Zimmer

NBER Working Paper No. 14842

April 2009

JEL No. C21,H75,I21

\begin{abstract}
The purpose of this paper is to study identification and estimation of causal effects in experiments with multiple sources of noncompliance. This research design arises in many applications in education when access to oversubscribed programs is partially determined by randomization. Eligible households decide whether or not to comply with the intended treatment. The paper treats program participation as the outcome of a decision process with five latent household types. We show that the parameters of the underlying model of program participation are identified. Our proofs of identification are constructive and can be used to design a GMM estimator for all parameters of interest. We apply our new methods to study the effectiveness of magnet programs in a large urban school district. Our findings show that magnet programs help the district to attract and retain students from households that are at risk of leaving the district. These households have higher incomes, are more educated, and have children that score higher on standardized tests than households that stay in district regardless of the outcome of the lottery.
\end{abstract}

\author{
John Engberg \\ Rand Corporation \\ 4570 5th Avenue \\ Pittsburgh, PA 15213 \\ engberg@rand.org \\ Dennis Epple \\ Tepper School of Business \\ Carnegie Mellon University \\ Posner Hall, Room 257B \\ Pittsburgh, PA 15213 \\ and NBER \\ epple@cmu.edu \\ Jason Imbrogno \\ Tepper School of Business \\ Carnegie Mellon University \\ Pittsburgh, PA 15213 \\ jpi@cmu.edu
}

\author{
Holger Sieg \\ Tepper School of Business \\ Carnegie Mellon University \\ 5000 Forbes Avenue \\ Pittsburgh, PA 15213-3890 \\ and NBER \\ holgers@andrew.cmu.edu
}

Ron Zimmer

Erickson Hall

Michigan State University

East Lansing, MI 48824

rzimmer@msu.edu 


\section{Introduction}

The purpose of this paper is to study identification and estimation of causal effects in experiments with multiple sources of noncompliance. In a standard experimental design, each subject agrees to participate in the experiment and randomization completely determines whether the individual is assigned to the treatment or the control group. ${ }^{1}$ In our design, randomization gives potential participants the option to participate in the program, i.e. individuals that win a lottery can choose whether or not to participate in the program. Individuals thus decide whether or not to comply with the intended treatment. This type of research design arises in many applications in education. ${ }^{2}$ Many school districts use lotteries to determine access to over-subscribed educational programs. Lottery winners are accepted into the program, with the ultimate choice of attendance left to the student and his family. Households have many different outside options and as consequence there are different reasons for noncompliance. Lottery losers do not have the option to participate in the program. Program participation then depends on lottery outcomes as well as on household decisions.

We follow the literature on program evaluation and allow for heterogeneity in the effect of treatment. This approach was introduced into economics by Quandt (1972), Heckman (1978) and Lee (1979). ${ }^{3}$ This approach shares many similarities with the causal model of potential outcomes introduced by Rubin (1974) into the statistical literature. Our approach of modeling noncompliance in experimental designs builds on the work by Angrist, Imbens, and Rubin (1996) (AIR) who also study an ex-

\footnotetext{
${ }^{1}$ See, for example, Heckman and Vytlacil (2007) for an overview of the program evaluation literature.

${ }^{2}$ Angrist (1990) introduced the use of lotteries to study the impact of military service on earnings. Of course, in his application program participation is mandatory: the penalties of avoiding the draft were quite significant.

${ }^{3}$ Heckman and Robb (1985) and Bjorklund and Moffitt (1987) treated heterogeneity in treatment as a random coefficients model.
} 
perimental design in which compliance is not perfect: some individuals assigned to treatment do not take it, and some not assigned to treatment do take it. They refer to the two non-complying types as "never-takers" and "always-takers." There is also a third type that does exactly what its assignment requires. These are referred to as "compliers."

Our approach focuses on experimental designs that arise in educational economics. Our application focuses on the effectiveness of magnet programs. To study these experimental designs, we generalizes the framework by allowing for additional types of non-compliance. These additional types arise because households face two outside options: they can send their children to a non-magnet school within the school district or they can leave the school district. If there are no schooling options outside the the public school district, our model simplifies to the one considered in AIR.

Since we need to account for two different sources of non-compliance, our model has five latent types. The first type is a "complying stayer" who chooses the magnet program if it wins. The second type is a "non-complying stayer" who does not choose the magnet program even if he wins the lottery. Both of these types stay in the district whether they lose the lottery. ${ }^{4}$ The third and forth types leave the district if they lose the lottery. The third type is a "leaver" and will not enroll its child in the district independently of the outcome of the lottery. ${ }^{5}$ The fourth type complies with the lottery and participates in the magnet program if it wins the lottery. We denote these households as "at risk." Given that many urban school districts are

\footnotetext{
${ }^{4}$ The district offers a standard education program to all households that do not win the lottery.

${ }^{5}$ Households have incomplete information and need to gather information to learn about the features of different programs. Households have to sign up for lotteries months in advance. At that point, they dot not have accumulated all relevant information. Once they have accumulated all relevant information, they may decide to opt out of the public school system since their preferred choice dominates the program offer by the district. Note that there are typically no penalties in participating in the lottery and declining to participate in the the program.
} 
experiencing declining enrollment, this type is important from a policy perspective. Finally, there is a fifth type that always takes the magnet option regardless of the outcome of the lottery. The household types are latent, i.e. unobserved by both the researcher and the school district administrators.

One key objective of the analysis is then to identify and estimate the proportions of these five latent types and to characterize differences in observed characteristics among these types. Estimating these parameters allows to study whether magnet schools are effective in attracting and retaining students and households. We show that the parameters of the underlying framework of program participation are nonparametrically identified. Our proofs of identification are constructive and can be used to design a GMM estimator for all parameters of interest (with respect to retention.) We can thus study the effectiveness of various programs that try to attract and retain students.

We then investigate whether we can identify and estimate the causal effect of the program on other potential outcomes such as achievement, attainment, or suspension. Evaluating the effectiveness of the program on these other outcomes is more difficult due to the underlying selection problems. We provide conditions that allow us to identify and estimate (local) average treatment effects for "complying stayers." We also show that it is impossible to identify the effects for "students at risk" without imposing additional assumptions on the selection process. One key result in AIR is that the standard instrumental variables regression using random assignment as an instrument gives the local average treatment effect for compliers. In our research design the standard IV estimator only yields a consistent estimator of the (local) average treatment effect, if the fraction of "at risk households" is negligible, i.e. if we only have one type of "compliers." If there are two different types of compliers the IV estimator does not identity a local average treatment effect.

Our estimation approach is also closely related to linear IV estimators that have 
been commonly used in the related empirical literature to study attraction and retention effects. ${ }^{6}$ We show in this paper that two of the most popular linear estimators have well-defined interpretations within our framework of program participation. We derive the probability limits of the standard "intend-to-treat" OLS estimator and the IV estimator, that uses the outcome of the lottery as an instrument for program participation. ${ }^{7}$ We show that the probability limits of these estimators are functions of the parameters of our framework. The GMM estimator that we develop is more comprehensive and provides full identification of all parameters of interest. Our approach thus provides a unified interpretation of most commonly used linear estimators. More importantly, it also provides additional insights that are outside the scope of traditional linear estimators.

We apply the techniques developed in this paper to study the effectiveness of magnet programs in a mid-sized urban school district. While debates surrounding the effectiveness of other school choice options such as charter schools and educational vouchers have grabbed much attention from researchers and policymakers, magnet programs have gotten less attention despite the fact that they are much more prevalent than charter schools or educational voucher programs. A second objective of this

\footnotetext{
${ }^{6}$ Cullen, Jacob, and Levitt (2006), for example, have advocated in a recent, influential study the use of linear estimators to analyze open enrollment school choice in the Chicago Public Schools. Lotteries were also used by Rouse (1998) to study the impact of the Milwaukee voucher program. Hoxby and Rockoff (2004) also use lotteries to study Chicago charter schools. These estimators have been used by Ballou, Goldring, and Liu (2006) to examine a magnet program. Hastings, Kane, and Staiger (2006) estimate a model of school choice based on stated preferences for schools in Charlotte. Since school attendance was partially the outcome of a lottery, they use the lottery outcomes as instruments to estimate the impact of attending the first choice school. Angrist, Bettinger, Bloom, King, and Kremer (2002) study the effects of vouchers when there is randomization in selection of recipients from the pool of applicants.

${ }^{7}$ Angrist and Imbens (1994) discuss identification and estimation of local treatment effects. Heckman and Vytlacil (2005) provide a general framework for econometric policy evaluation.
} 
paper is to provide new research to understand the causal effects of magnet programs. Our application focuses on magnet programs operated by a mid-sized urban school district. Our findings show that magnet programs help the district to attract and retain students from households that are at risk of leaving the district. These households have higher incomes, are more educated, and have children that score higher on standardized tests than households that stay in district regardless of the outcome of the lottery. These households have many options outside the public school system, but apparently, they view the existing magnet programs as desirable programs for their children. We also find evidence that the market for elementary school competition is more competitive than the market for middle and high school education. The fraction of households at risk declines with age of the students. Magnet programs are most effective in attracting households that have young school-age children.

The rest of the paper is organized as follows. Section 2 develops our new methods for estimation of treatment effects when program participation is partially determined by lotteries. We discuss identification and estimation. We also show that commonly used linear IV estimators can be interpreted as partially identifying different components of our framework. Section 3 provides some institutional background for our application and discusses our main data sources. Section 4 reports the empirical findings of our paper. Finally, we offer some conclusions and discuss the policy implications of our work in Section 5.

\section{Identification and Estimation of Causal Effects}

\subsection{The Research Design}

We consider a research design in which program participation is only partially determined by randomization, i.e. a design with multiple sources of noncompliance. These 
designs arise when randomization occurs at the application stage. An applicant that receives a favorable random draw in the lottery has the option to participate in the program. But winning applicants are not required to participate and hence can opt out before the program begins. This design thus differs from the standard experimental design in which randomization occurs after individuals have already committed to participate in the program. Since our application focuses on magnet school, we will develop our methods within this context. However, the methods derived in this paper apply quite broadly and are not restricted to the application that we study.

Consider the problem of a household that has to decide whether or not to enroll a student in a magnet program offered by a school district. ${ }^{8}$ We only consider households that have decided to participate in a lottery which determines access to the program. Let $W$ denote a discrete random variable which is equal to 1 if the student wins the lottery and 0 if it loses. Let $w$ denote the fraction of households that win the lottery. A student that wins the lottery has three options: participate in the program, participate in a different program offered by the same school district, or leave the district and pursue educational opportunities outside the district. A student that loses has only the last two options. Let $M$ be 1 if a student attends the (magnet) program and 0 otherwise. Finally, let $A$ denote a random variable that is one if a student attends a school in the district and 0 otherwise.

The key idea behind our method is to use five latent types to classify households into compliers and non-compliers. We make the following assumption

\section{Assumption 1}

1. Let $s_{m}$ denote the fraction of "complying stayers." These households will remain in the district when they lose the lottery. If they win the lottery, they comply

\footnotetext{
${ }^{8}$ We use the terms "household" to describe the decision maker and "student" to describe the person that participates in the program.
} 
with the intended treatment and attend the magnet school.

2. Let $s_{n}$ denote the fraction of "noncomplying stayers." These households will remain in the district when they lose the lottery. If they win the lottery, they will not comply with the intended treatment and attend a non-magnet school in the school district.

3. Let l denote the fraction of "leavers." These are households that will leave the district regardless of whether they are admitted to the magnet program.

4. Let $r$ denote the fraction that is "at risk." These households will remain in the district and attend the magnet program if admitted to the magnet program, and they will leave the district otherwise.

5. Let $a_{t}$ denote the fraction of "always-takers." They will attend the magnet school regardless of the outcome of the lottery.

Comparing our approach to the one developed in AIR, note that we have two types of "never-takers" that we denote by "noncomplying stayers" and "leavers." Similarly we have two types of "compliers" that we denote by "complying stayers" and "at risk households." The main difference thus arises because individuals have two outside options instead of one as assumed in AIR. If we assume that there are no school options outside the district, i.e. if $l=r=0$, then our experimental design is identical to the one studied in AIR.

Since the household type is latent, one key empirical problem is identifying and estimating the proportions of each type in the underlying population. If we can accomplish this goal, we can study the effectiveness of magnet programs in attracting and retaining households that participate in the lottery. Moreover, we are often interested in how these types of households differ along observed characteristics. For example, we would like to test the hypothesis that households that are classified to 
be "at risk" are more likely to have higher levels of income than "stayers." Hence we would like to characterize the type of households that are most likely to leave if they are not offered a place in the magnet program.

To formalize these ideas, consider a random variable $X$ that measures an observed household characteristic such as income or socio-economic status. Appealing to our decomposition, let $\mu_{r}, \mu_{s_{m}}, \mu_{s_{n}}, \mu_{l}$ and $\mu_{a_{t}}$ denote the mean of random variable $X$ conditional on belonging to group $r, s_{n}, s_{m}, l$, and $a$ respectively. The goal of the first part of the analysis is then to identify and estimate the following eleven parameters $\left(w, r, s_{n}, s_{m}, l, a, \mu_{r}, \mu_{s_{m}}, \mu_{s_{n}}, \mu_{l}, \mu_{a_{t}}\right){ }^{9}$

In addition to studying the effectiveness of magnet programs on attraction and retention of students, we also like to study the effects of the program on other student outcomes. Let $T$ be an outcome measure of interest, for example, the score on a standardized achievement test. Following Fisher (1935), we adopt standard notation in the program evaluation literature and consider a model with three potential outcomes:

$$
T=A M T_{1}+A(1-M) T_{0}+(1-A) T_{2}
$$

where $T_{1}$ denotes the outcome if the student attends the magnet school and $T_{0}$ if he attends a different program in the district where $T_{2}$ denotes the outcome outside of the public schools. ${ }^{10}$ We will later assume that $T$ is not observed for students that do not attend a public school within the district, i.e. if $A=0$, then $T$ is not observed. This assumption is plausible since researchers have typically only access to data from one school district. Private schools rarely provide access to their confidential data.

\footnotetext{
${ }^{9}$ It is straight forward to allow $X$ to be a vector.

${ }^{10}$ This model is often referred to as the switching regression model due to Quandt (1972) and Maddala (1983). It also known in the statistical literature as the Rubin Model developed in Rubin (1974, 1978). It also shares many similarities with the Roy Model as discussed in Heckman (1979) and Heckman and Honore (1990).
} 
Attention, therefore, focuses on the treatment effect $\Delta=T_{1}-T_{0}$. Note that $\Delta$ is unobserved for all students. Conceptually, we can define five different average treatment effects, one for each latent group. ${ }^{11}$

$$
A T E_{\text {Type }}=E\left[T_{1}-T_{0} \mid \text { Type }=1\right] \quad \text { Type } \in\left\{S_{n}, S_{m}, R, L, A_{t}\right\}
$$

We also study whether we can identify and estimate these types of treatment effects.

\subsection{Identification}

First we need to establish the information set of the researcher.

Assumption 2 The researcher observes probabilities and conditional means for the following eight outcomes:

Table 1: Observed Outcomes

\begin{tabular}{|l|l|l|l|l|l|}
\hline & $\mathrm{W}$ & $\mathrm{M}$ & $\mathrm{A}$ & $\operatorname{Pr}\{W, M, A\}$ & $E[X \mid W, M, A]=E[X \mid M, A]$ \\
\hline I & 1 & 1 & 1 & $w\left(r+s_{m}+a_{t}\right)$ & $\frac{r \mu_{r}+s_{m} \mu_{s_{m}}+a_{t} \mu_{a_{t}}}{r+s_{m}+a_{t}}$ \\
\hline II & 1 & 1 & 0 & not possible & \\
\hline III & 1 & 0 & 1 & $w s_{n}$ & $\mu_{s_{n}}$ \\
\hline IV & 1 & 0 & 0 & $w l$ & $\mu_{l}$ \\
\hline V & 0 & 1 & 1 & $(1-w) a_{t}$ & $\mu_{a_{t}}$ \\
\hline VI & 0 & 1 & 0 & not possible & \\
\hline VII & 0 & 0 & 1 & $(1-w)\left(s_{n}+s_{m}\right)$ & $\frac{s_{n} \mu_{s_{n}+s_{m} \mu_{s_{m}}}}{s_{n}+s_{m}}$ \\
\hline VIII & 0 & 0 & 0 & $(1-w)(r+l)$ & $\frac{r \mu_{r}+l \mu_{l}}{r+l}$ \\
\hline
\end{tabular}

\footnotetext{
${ }^{11}$ There are other effects that may also be of interest such as treatment effect on the treated or the marginal treatment effect. For a discussion see, among others, Heckman and Vytlacil (2005) and Moffitt (2008).
} 
Note that only six of the eight outcomes listed in Table 1 are possible.

Identification can be established sequentially. First, we discuss identification of the probabilities that characterize the shares of the latent types. We have the following result.

Lemma 1 The parameters $\left(w, r, s_{n}, s_{m}, l, a\right)$ are identified by the six non-degenerate probabilities in Table 1.

Proof: Parameter $w$ is the fraction that wins the lottery:

$$
\begin{array}{r}
w=\operatorname{Pr}(W=1, M=1, A=1)+\operatorname{Pr}(W=1, M=1, A=0) \\
\quad+\operatorname{Pr}(W=1, M=0, A=1)+\operatorname{Pr}(W=1, M=0, A=0)
\end{array}
$$

Given $w, s_{n}$ is identified from $(1,0,1)$ :

$$
s_{n}=\operatorname{Pr}(W=1, M=0, A=1) / w
$$

$l$ is identified from $(1,0,0)$ :

$$
l=\operatorname{Pr}(W=1, M=0, A=0) / w
$$

$a_{t}$ is identified from $(0,1,1)$ :

$$
a_{t}=\operatorname{Pr}(W=0, M=1, A=1) /(1-w)
$$

Given $w$ and $s_{n}, s_{m}$ is identified form $(0,0,1)$ :

$$
s_{m}=\operatorname{Pr}(W=0, M=0, A=1) /(1-w)-s_{n}
$$

Given $a_{t}, l, s_{n}, s_{m}, r$ is identified of the identity:

$$
r=1-l-s_{m}-s_{n}-a_{t}
$$

Q.E.D. 
Note that there is no over-identification at this stage since the six probabilities in Table 1 add up to one, and the last three non-degenerate probabilities add up to $1-w$. Next we discuss identification of the four conditional means. We have the following result.

Lemma 2 Given $\left(w, r, s_{n}, s_{m}, l, a_{t}\right)$, the parameters $\left(\mu_{r}, \mu_{s_{m}}, \mu_{s_{n}}, \mu_{l}, \mu_{a_{t}}\right)$ are identified by the five non-degenerate conditional expectations observed in Table 1.

Proof: $\mu_{l}$ is identified from $(1,0,0)$ :

$$
\mu_{l}=E(X \mid W=1, M=0, A=0)=E(X \mid M=0, A=0)
$$

Similarly $\mu_{s_{n}}$ is identified from $(1,0,1)$ :

$$
\mu_{s_{n}}=E(X \mid W=1, M=0, A=1)=E(X \mid M=0, A=1)
$$

and $\mu_{a_{t}}$ is identified from $(0,1,1)$ :

$$
\mu_{a_{t}}=E(X \mid W=0, M=1, A=1)
$$

Given $\mu_{s_{n}}, \mu_{s_{m}}$ is identified from $(0,0,1)$ :

$$
\mu_{s_{m}}=\left[\left(s_{n}+s_{m}\right) E(X \mid W=0, M=0, A=1)-s_{n} \mu_{s_{n}}\right] / s_{m}
$$

Given $\mu_{s_{m}}$ and $\mu_{a_{t}}, \mu_{r}$ is identified from $(1,1,1)$ :

$$
\mu_{r}=\left[\left(r+s_{m}+a_{t}\right) E(X \mid W=0, M=0, A=1)-s_{m} \mu_{s_{m}}-a_{t} \mu_{a_{t}}\right] / r
$$

Q.E.D.

Note that there is one over-identifying condition at this stage. This restriction arises due to the condition that $W$ is orthogonal to $X .^{12}$

Lemma 1 and Lemma 2 then imply the following result:

\footnotetext{
${ }^{12}$ The lotteries are assumed to be fair and blind in the sense that the district does not pre-select winners and losers based on beliefs about attendance or any socio-economic or student characteristic found in $X$.
} 
Proposition 1 The parameters $\left(w, r, s_{n}, s_{m}, l, a_{t}, \mu_{r}, \mu_{s_{m}}, \mu_{s_{n}}, \mu_{l}, \mu_{a_{t}}\right)$ are identified.

We now turn to the analysis of identification of causal treatment effects of magnet programs on educational and behavioral outcomes. We make the following assumption regarding observables:

Assumption 3 We assume that the researcher only observes outcomes, T, for students that remain in the school district, i.e. we do not observe outcomes for "leavers" and "at risk households" that lose the lottery.

It is useful to assume initially that we observe the latent household type. Table 2 provides a summary of the relevant conditional expectations. ${ }^{13}$ Conditioning on lottery outcomes, there are eight conditional expectations. Three of these pertain to outcomes that are not observed if we observed the latent type since students in these latent groups leave the school district. The remaining five conditional expectations relate to household types that remain in the district.

Table 2: Mean Outcomes Conditional on Type

\begin{tabular}{|l|l|l|l|l|l|}
\hline & $\begin{array}{l}\text { Complying } \\
\text { Stayers }\end{array}$ & $\begin{array}{l}\text { Non-Complying } \\
\text { Stayers }\end{array}$ & At Risk & Leavers & $\begin{array}{l}\text { Always } \\
\text { Takers }\end{array}$ \\
\hline$W=1$ & $E\left[T_{1} \mid S_{m}=1\right]$ & $E\left[T_{0} \mid S_{n}=1\right]$ & $E\left[T_{1} \mid R=1\right]$ & $E\left[T_{2} \mid L=1\right]$ & $E\left[T_{1} \mid A_{t}=1\right]$ \\
$W=0$ & $\left.E\left[T_{0}\right] S_{m}=1\right]$ & $E\left[T_{0} \mid S_{n}=1\right]$ & $E\left[T_{2} \mid R=1\right]$ & $E\left[T_{2} \mid L=1\right]$ & $E\left[T_{1} \mid A_{t}=1\right]$ \\
\hline
\end{tabular}

Note that $T_{2}$ is never observed.

\footnotetext{
${ }^{13}$ Note that we are implicitly assuming that the mean performance of stayers who would decline lottery admission is the same whether they win or lose the lottery, i.e. $E\left[T_{0} \mid S_{n}=1, W=1\right]=$ $E\left[T_{0} \mid S_{n}=1, W=0\right]=E\left[T_{0} \mid S_{n}=1\right]$.
} 
From Table 2, it is evident that even if we observed the latent type, there is little hope in identifying $A T E_{S_{n}}, A T E_{R}, A T E_{L}$, or $A T E_{A_{t}}$ without imposing some additional assumptions on the underlying selection process. For stayers that never attend the magnet program, we cannot identify $E\left[T_{1} \mid S_{m}=1\right]$. For students at risk, we cannot identify $E\left[T_{0} \mid R=1\right]$. For leavers, we can neither identify $E\left[T_{1} \mid L=1\right]$ nor $E\left[T_{0} \mid L=1\right]$. For always-takers we never observe $E\left[T_{0} \mid A_{t}=1\right]$. We thus have the following result:

Proposition 2 Without imposing additional assumptions on the selection of students into latent groups, $A T E_{S_{n}}, A T E_{R}, A T E_{L}$ and $A T E_{A_{t}}$ are not identified.

Attention, therefore, focuses on identification of $A T E_{S_{m}}$.

Since we do not observe the latent type, Assumption 3 implies that we only observe mean outcomes for the students conditional on $W, M$ and $A$. For students who win the lottery and attend the magnet school, we observe

$E\left[T_{1} \mid W=1, M=1, A=1\right]=\frac{s_{m} E\left[T_{1} \mid S_{m}=1\right]+r E\left[T_{1} \mid R=1\right]+a_{t} E\left[T_{1} \mid A_{t}=1\right]}{s_{m}+r+a_{t}}$

For students who lose the lottery and attend the magnet school, we observe

$$
E\left[T_{1} \mid W=0, M=1, A=1\right]=E\left[T_{1} \mid A_{t}=1\right]
$$

We also observe mean performance of stayers who lose the lottery:

$$
E\left[T_{0} \mid W=0, M=0, A=1\right]=\frac{s_{m} E\left[T_{0} \mid S_{m}=1\right]+s_{n} E\left[T_{0} \mid S_{n}=1\right]}{s_{m}+s_{n}}
$$

Finally we also observe the mean performance of stayers who win the lottery and decline to enroll in the magnet program:

$$
E\left[T_{0} \mid W=1, M=0, A=1\right]=E\left[T_{0} \mid S_{n}=1\right]
$$

Equations (16) and (17) imply that we can identify $E\left[T_{0} \mid S_{m}=1\right]$ and $E\left[T_{0} \mid S_{n}=1\right]$, since $s_{n}$ and $s_{m}$ have been identified before. Equations (15 implies that we can identify 
$E\left[T_{1} \mid A_{t}=1\right]$. However equation (14) then implies that it is difficult to separately identify $E\left[T_{1} \mid S_{m}=1\right]$ and $E\left[T_{1} \mid R=1\right]$. As a consequence we have the following result:

\section{Proposition 3}

i) $E\left[T_{0} \mid S_{m}=1\right], E\left[T_{0} \mid S_{n}=1\right]$ and $E\left[T_{1} \mid A_{t}=1\right]$ are identified.

ii) If $r=0$, then $E\left[T_{1} \mid S_{m}=1\right]$ and $A T E_{S_{m}}$ are identified.

iii) If $r \neq 0$ and $E\left[T_{1} \mid S_{m}=1\right]=E\left[T_{1} \mid R=1\right]$, then ATE $E_{s_{m}}$ is identified.

iv) If $r \neq 0$ and $E\left[T_{1} \mid S_{m}=1\right] \neq E\left[T_{1} \mid R=1\right]$, then $A T E_{s_{m}}$ is not identified without imposing further assumptions.

We offer the following observations:

a) Recall that if $r=l=0$ are research design simplifies to the one considered in AIR. This case is covered in Proposition 3 (i) and (ii).

b) Attrition per se is not the problem. If membership in the at risk group is negligible (i.e., $r=0$ ), identification is achieved even if the fraction of leavers, $l>>0$, is large.

c) If controlling on observables is sufficient to deal with the selection problem, a matching approach can be justified. ${ }^{14}$ We can thus generalize the result in Proposition 3 (iii) by conditioning on $X$.

d) The lack of identification discussed in Proposition 3 (iv) arises from the at risk group. If stayers and at risk students differ by unobserved characteristics, we have a standard selection problem.

e) If we assume that $E\left[T_{1} \mid S_{m}=1\right] \leq E\left[T_{1} \mid R=1\right]$, then equation (14) implies that

$$
\frac{\left(s_{m}+r+a_{t}\right) E\left[T_{1} \mid W=1, M=1, A=1\right]-a_{t} E\left[T_{1} \mid A_{t}\right]}{s_{m}+r} \geq E\left[T_{1} \mid S_{m}=1\right]
$$

and we can construct an upper bound for $A T E_{s_{m}}$.

\footnotetext{
${ }^{14}$ For a discussion of matching estimators, see, among others, Rosenbaum and Rubin (1983), Heckman, Ichimura, and Todd (1997), and Abadie and Imbens (2006).
} 


\section{$2.3 \quad$ A GMM Estimator}

Suppose we observe a random sample of $N$ applicants to a magnet program, indexed by $i$. We view these as $N$ independent draws from the underlying population of all applicants to this magnet program. Let $W_{i}, M_{i}, A_{i}, X_{i}$ now denote the random variables that correspond to observation $i$.

Note that the proofs of identification are constructive. Replacing population means by sample means thus yields consistent estimators for the parameter of interests. Nevertheless it is useful to place the estimation problem with a well defined GMM framework. This allows us to estimate simultaneously all parameters and compute asymptotic standard errors. We can estimate the fractions of each latent type based on moment conditions derived from the choice probabilities in Table 1.

$$
\begin{aligned}
& \frac{1}{N} \sum_{i=1}^{N}\left[W_{i} M_{i} A_{i}-w\left(r+s_{m}+a_{t}\right)\right] \\
& \frac{1}{N} \sum_{i=1}^{N}\left[W_{i}\left(1-M_{i}\right) A_{i}-w s_{n}\right] \\
& \frac{1}{N} \sum_{i=1}^{N}\left[W_{i}\left(1-M_{i}\right)\left(1-A_{i}\right)-w l\right] \\
& \frac{1}{N} \sum_{i=1}^{N}\left[\left(1-W_{i}\right) M_{i} A_{i}-(1-w) a_{t}\right] \\
& \frac{1}{N} \sum_{i=1}^{N}\left[\left(1-W_{i}\right)\left(1-M_{i}\right) A_{i}-(1-w)\left(s_{n}+s_{m}\right)\right]
\end{aligned}
$$

Similarly we can estimate the mean characteristics of each type based on the following moment conditions.

$$
\begin{aligned}
& \frac{1}{N} \sum_{i=1}^{N}\left[W_{i} M_{i} A_{i} X_{i}-w\left(r+s_{m}+a_{t}\right) \frac{r \mu_{r}+s_{m} \mu_{s_{m}}+a_{t} \mu_{a_{t}}}{r+s_{m}+a_{t}}\right] \\
& \frac{1}{N} \sum_{i=1}^{N}\left[W_{i}\left(1-M_{i}\right) A_{i} X_{i}-w s_{n} \mu_{s_{n}}\right] \\
& \frac{1}{N} \sum_{i=1}^{N}\left[W_{i}\left(1-M_{i}\right)\left(1-A_{i}\right) X_{i}-w l \mu_{l}\right]
\end{aligned}
$$




$$
\begin{aligned}
& \frac{1}{N} \sum_{i=1}^{N}\left[\left(1-W_{i}\right) M_{i} A_{i} X_{i}-(1-w) a_{t} \mu_{a_{t}}\right] \\
& \frac{1}{N} \sum_{i=1}^{N}\left[\left(1-W_{i}\right)\left(1-M_{i}\right) A_{i} X_{i}-(1-w)\left(s_{n}+s_{m}\right) \frac{s_{n} \mu_{s_{n}}+s_{m} \mu_{s_{m}}}{s_{n}+s_{m}}\right] \\
& \frac{1}{N} \sum_{i=1}^{N}\left[\left(1-W_{i}\right)\left(1-M_{i}\right)\left(1-A_{i}\right) X_{i}-(1-w)(r+l) \frac{r \mu_{r}+l \mu_{l}}{r+l}\right]
\end{aligned}
$$

Hence the parameters of the model can be estimated using a GMM estimator (Hansen, 1982). ${ }^{15}$ Note that the estimator above easily generalizes to the case in which $X$ is vector of random variables. We simply stack all orthogonality conditions to obtain a simultaneous estimator that exploits all relevant orthogonality conditions.

\subsection{Interpreting Commonly Used OLS and IV Estimators}

There exists a close relationship between the GMM estimator discussed above and some more commonly used OLS and IV estimators. Here we assume that $a_{t}=0$ which is consistent with most applications in educational economics. To simplify notation, let $s=s_{n}+s_{m}$ denote the total fraction of stayers.

First, we consider an estimator that is also some called the "intend-to-treat" estimator since it does not account for actual program participation. We have the following result:

\section{Proposition 4}

Consider the linear regression model:

$$
A_{i}=\beta_{0}+\beta_{1} W_{i}+u_{i}
$$

where $E\left[u_{i} \mid W_{i}\right]=0$. Let $\hat{\beta}_{0}$ and $\hat{\beta}_{1}$ be the probability limits of the least squares estimators. Under standard regularity assumptions $\hat{\beta}_{0}=s+a_{t}$ and $\hat{\beta}_{1}=r$.

\footnotetext{
${ }^{15}$ There are other feasible estimators. For example, one can replace one of the equation with the orthogonality conditions $\frac{1}{N} \sum_{i=1}^{N}\left[W_{i}-w\right]$.
} 
The intercept is the sum of the proportion who are stayers and the proportion who are always takers. The slope of the OLS equation is the fraction of at-risk students in the magnet school applicant pool.

Proof: Let $a$ denote the proportion of magnet applicants that attend school in the district. From the definitions given at the outset: $a=s+w r+a_{t}$. Let $q$ denote the fraction of students that win the lottery and attend a school in the district. Then, from the definitions presented at the outset: $q=w\left(r+s+a_{t}\right)$.

Consider the normal equations of the least squares estimators. After dividing by total number of students and taking limits, we obtain:

$$
\left[\begin{array}{l}
a \\
q
\end{array}\right]=\left[\begin{array}{ll}
1 & w \\
w & w
\end{array}\right]\left[\begin{array}{l}
\hat{\beta}_{0} \\
\hat{\beta}_{1}
\end{array}\right]
$$

or

$$
\left[\begin{array}{l}
\hat{\beta}_{0} \\
\hat{\beta}_{1}
\end{array}\right]=\left[\begin{array}{ll}
1 & w \\
w & w
\end{array}\right]^{-1}\left[\begin{array}{l}
a \\
q
\end{array}\right]=\frac{1}{1-w}\left[\begin{array}{c}
a-q \\
\frac{1}{w} q-a
\end{array}\right]
$$

Consider $\hat{\beta}_{1}$ in more detail:

$$
\hat{\beta}_{1}=\frac{1}{1-w}\left(\frac{1}{w} q-a\right)=\frac{1}{w(1-w)}\left(w\left(r+s+a_{t}\right)-w\left(s+w r+a_{t}\right)\right)=r
$$

The intercept is:

$$
\hat{\beta}_{0}=\frac{a-q}{1-w}=\frac{s+w r+a_{t}-w\left(r+s+a_{t}\right)}{1-w}=s+a_{t}
$$

Q.E.D.

Next we consider a linear IV estimator that uses the outcome of the lottery as an instrument from program participation. This estimator is the preferred estimator in most empirical studies and has, for example, been advocated by Cullen et al. (2006).

Proposition 5 Consider the linear regression model

$$
A_{i}=\gamma_{0}+\gamma_{1} M_{i}+v_{i}
$$


where $E\left[v_{i} \mid W_{i}\right]=0$, i.e. $W_{i}$ is used as an instrument for $M_{i}$. Let $\hat{\gamma}_{0}$ and $\hat{\gamma}_{1}$ denote the probability limits of the standard exactly identified linear IV estimator. Under standard regularity assumptions we have $\hat{\gamma}_{0}=s+a_{t}$ and $\hat{\gamma}_{1}=\frac{r w}{m}$, where $m$ is the fraction of magnet school applicants who subsequently attend a magnet school.

The intercept is again the sum of the proportion who are stayers and the proportion who are always takers. The slope of the IV equation is the fraction of magnet school attendees who are at-risk students.

Proof: Consider the normal equations for the standard IV estimator. ${ }^{16}$ After dividing by total number of students and taking limits, we obtain:

$$
\left[\begin{array}{l}
a \\
q
\end{array}\right]=\left[\begin{array}{ll}
1 & m \\
w & m
\end{array}\right]\left[\begin{array}{l}
\hat{\gamma}_{0} \\
\hat{\gamma}_{1}
\end{array}\right]
$$

Now:

$$
\begin{aligned}
a & =s+w r+a_{t} \\
m & =w\left(r+s_{m}\right)+a_{t} \\
q & =w\left(r+s+a_{t}\right)
\end{aligned}
$$

Substituting these into the above normal equations, we obtain:

$$
\left[\begin{array}{l}
\hat{\gamma}_{0} \\
\hat{\gamma}_{1}
\end{array}\right]=\left[\begin{array}{cc}
1 & m \\
w & m
\end{array}\right]^{-1}\left[\begin{array}{l}
a \\
q
\end{array}\right]=\frac{1}{1-w}\left[\begin{array}{l}
a-q \\
\frac{1}{m} q-\frac{w}{m} a
\end{array}\right]
$$

Hence,

$$
\widehat{\gamma}_{1}=\frac{q-w a}{m(1-w)}=\frac{w\left(r+s+a_{t}\right)-w\left(s+w r+a_{t}\right)}{m(1-w)}=\frac{r w}{m}
$$

and

$$
\widehat{\gamma}_{0}=\frac{a-q}{1-w}=\frac{\left(s+a_{t}\right)(1-w)}{(1-w)}=s+a_{t}
$$

\footnotetext{
${ }^{16}$ In standard textbook notation these are $Z^{\prime} y=Z^{\prime} X \widehat{\gamma}$.
} 
Q.E.D.

Finally, we consider the linear model:

$$
T_{i}=\alpha_{0}+\alpha_{1} M_{i}+w_{i}
$$

We consider properties of the standard IV estimator that uses $W_{i}$ as an instrument for $M_{i}$. Following Durbin (1954) the IV estimator is defined as the ratio of sample covariances:

$$
\begin{aligned}
{\hat{\alpha_{1}}}^{I V} & =\frac{\widehat{\operatorname{cov}}(T, W)}{\widehat{\operatorname{cov}}(M, W)} \\
& =\frac{\sum_{i=1}^{N} T_{i} W_{i} / \sum_{i=1}^{N} W_{i}-\sum_{i=1}^{N} T_{i}\left(1-W_{i}\right) / \sum_{i=1}^{N}\left(1-W_{i}\right)}{\sum_{i=1}^{N} M_{i} W_{i} / \sum_{i=1}^{N} W_{i}-\sum_{i=1}^{N} M_{i}\left(1-W_{i}\right) / \sum_{i=1}^{N}\left(1-W_{i}\right)}
\end{aligned}
$$

where $\widehat{c o v}$ denotes the sample covariance and the last equality follows from the binary nature of the instrument. We assume that the estimator is implemented using a random sample of students for which we observe $\left(T_{i}, M_{i}, W_{i}\right)$. In our application these are the students that are participating in a program offered by the district. The sample thus does not include students that left the district. We have the following result that parallels our finding in Proposition 3:

Proposition 6 If $r=0$, then

$$
\hat{\beta}^{I V} \rightarrow E\left[T_{1} \mid S_{m}\right]-E\left[T_{0} \mid S_{m}\right]
$$

If $r \neq 0$, the limit of the IV estimator does not converge to any of the commonly used treatment effects.

\section{Proof:}

Let $N$ denote the sample size, $N_{W}$ the number of students that win the lottery, $N_{W, M}$ the number of students that win the lottery and attend the program, and $N_{W, N M}$ the number of students that win the lottery and do not attend the program. We assume 
standard regularity conditions apply, so that sample means converge (almost surely) to population means.

Now consider the probability limits of the two key terms in the numerator of the IV estimator:

$$
\begin{aligned}
\frac{1}{N} \sum_{i=1}^{N} T_{i} W_{i}= & \frac{N_{W}}{N} \frac{1}{N_{W}} \sum_{i=1}^{N_{W}}\left[M_{i} T_{1 i}+\left(1-M_{i}\right) T_{i 0}\right] \\
= & \frac{N_{W}}{N}\left[\frac{N_{W, M}}{N_{W}} \frac{1}{N_{W, M}} \sum_{i=1}^{N_{W, M}} T_{1 i}+\frac{N_{W, N M}}{N_{W}} \frac{1}{N_{W, N M}} \sum_{i=1}^{N_{W, N M}} T_{0 i}\right] \\
\rightarrow & w\left[\frac{r}{r+s_{n}+s_{m}+a_{t}} E\left[T_{1} \mid R\right]+\frac{s_{m}}{r+s_{n}+s_{m}+a_{t}} E\left[T_{1} \mid S_{m}\right]\right. \\
& \left.+\frac{a_{t}}{r+s_{n}+s_{m}+a_{t}} E\left[T_{1} \mid A_{t}\right]+\frac{s_{n}}{r+s_{n}+s_{m}+a_{t}} E\left[T_{0} \mid S_{n}\right]\right] \\
= & w A
\end{aligned}
$$

and

$$
\begin{aligned}
\frac{1}{N} \sum_{i=1}^{N} T_{i}\left(1-W_{i}\right)= & \frac{N-N_{w}}{N} \frac{1}{N-N_{W}} \sum_{i=1}^{N-N_{w}} T_{0 i} \\
\rightarrow & (1-w)\left[\frac{s_{m}}{s_{m}+s_{n}+a_{t}} E\left[T_{0} \mid S_{m}\right]+\frac{s_{n}}{s_{m}+s_{n}+a_{t}} E\left[T_{0} \mid S_{n}\right]\right. \\
& \left.\quad+\frac{a_{t}}{s_{m}+s_{n}+a_{t}} E\left[T_{1} \mid A_{t}\right]\right] \\
= & (1-w) B
\end{aligned}
$$

Next consider the key terms in the denominator and note that:

$$
\begin{aligned}
\frac{1}{N} \sum_{i=1}^{N} M_{i} W_{i} & =\frac{N_{W}}{N} \frac{1}{N_{W}} \sum_{i=1}^{N_{W}} M_{i} \\
& =w \frac{s_{m}+r+a_{t}}{s_{m}+s_{n}+r+a_{t}} \\
& =w C
\end{aligned}
$$

and

$$
\begin{aligned}
\frac{1}{N} \sum_{i=1}^{N} M_{i}\left(1-W_{i}\right) & \rightarrow(1-w) \frac{a_{t}}{s_{m}+s_{n}+a_{t}} \\
& =(1-w) D
\end{aligned}
$$


As a consequence we have:

$$
\hat{\beta}^{I V} \rightarrow \frac{A-B}{C-D}
$$

Suppose $r=0$, then

$$
\hat{\beta}^{I V} \rightarrow E\left[T_{1} \mid S_{m}\right]-E\left[T_{0} \mid S_{m}\right]
$$

This effect can also be interpreted as a Local Average Treatment Effect since the students for which $S_{n}=1$ are the ones that will be affected by a change in the lottery outcome. Q.E.D.

Note that Angrist et al. (1996) consider the simplified version of our model with only three latent types assuming $l=r=0$. The IV estimator then identifies the Local Average Treatment Effect. In the more general case, the limit of the IV estimator depends of the mean outcomes of all five types and the relative proportions of these latent groups. Cullen et al. (2006) consider an application with $r \approx 0$. Hence the IV estimator used in that paper is consistent and can be used to estimate the relevant local treatment effects.

\section{Data}

Our application focuses on magnet programs that are operated by a mid-sized urban school district that prefers to not be idnetified. There are magnet programs for all grade levels, and each program has a slightly different focus. For example, there is an elementary school magnet program that focuses on international studies and the French language. We only consider magnet programs that are academically oriented. Every academic year, interested students submit applications for one magnet program of their choice. If the number of applications submitted during registration for any magnet program exceeds the number of available spaces, the district holds a lottery to determine the order in which applicants will be accepted. 
In the case of over-subscription, a computerized random selection determines each student's lottery number. The lottery is binding in the sense that students with lower numbers are accepted, higher numbered students are rejected. There is a clear cut-off number that separates the groups. We do not observe students attending magnet schools that lose the lottery. We therefore abstract from "always-takers" in the following analysis.

To preserve racial balance in the magnet programs, separate lotteries are held for black students and other students. Some programs also have preferences for students with siblings already attending the magnet programs. Separate lotteries are held for those students with an acceptable preference category for each magnet program. All in all, each lottery is held for a given program, in a given academic year, separately by race, and, finally, separately by preference code.

Table 3: Lottery Participant Characteristics

\begin{tabular}{|l|l|l|l|}
\hline Variable & Entire Sample & $\begin{array}{l}\text { Elementary School } \\
\text { Applicants Only }\end{array}$ & $\begin{array}{l}\text { High School } \\
\text { Applicants Only }\end{array}$ \\
\hline Math Test Score & $1304.9(207.9)[1049]$ & - & $1276.5(195.7)[627]$ \\
\hline Reading Test Score & $1310.2(244.4)[1048]$ & - & $1311.5(258.7)[627]$ \\
\hline Sex & $0.5123(0.5000)[2151]$ & $0.5121(0.5000)[871]$ & $0.5195(0.5000)[820]$ \\
\hline Race & $0.7209(0.4487)[2268]$ & $0.5691(0.4955)[912]$ & $0.8409(0.3660)[861]$ \\
\hline FRL & $0.3322(0.4711)[2161]$ & $0.3375(0.4731)[871]$ & $0.3195(0.4666)[820]$ \\
\hline Poverty & $0.2282(0.1407)[2162]$ & $0.2177(0.1358)[872]$ & $0.2344(0.1456)[820]$ \\
\hline Education & $0.2949(0.1933)[2162]$ & $0.3417(0.2253)[872]$ & $0.2513(0.1457)[820]$ \\
\hline Lottery Win & 64.8 & 56.3 & 78.3 \\
\hline
\end{tabular}

Listed as mean, (std dev), [observations] 
Lottery winners (lotteried-in) have the option to participate in the magnet program, with the ultimate choice of participation left to the student and his family. Lottery losers (lotteried-out) do not have this option, and thus must make their schooling choice without the availability of the magnet option. When winners decline admission, the students on the wait list become eligible. Again the rank on the wait list is determined by the original lottery. With a fair and balanced lottery, the winners and losers will be determined by chance, thus creating two groups that are similar to each other both on observable and unobservable characteristics.

The district granted us access to its longitudinal student database. This database currently has information from the 1998-1999 school year through 2006-2007. In addition to demographic data, the database contains detailed information about educational outcomes. This information is linked to each student by a unique ID number. The demographic characteristics for the students include race, sex, free/reduced lunch eligibility, and addresses. Using the addresses, we can assign census tract variables such as poverty and adult education levels to each student. We use two community characteristics that measure the socio-economic composition of the neighborhoods in which students reside. Poverty is the percentage of adults in the student's census tract with an income level below the poverty line. Education is the percentage of adults in the student's census tract with at least a college degree.

As pertaining to student educational outcomes, the database includes the school of attendance in each year, standardized test scores for the state assessment test. The database also contains the outcomes of the magnet lotteries. One of the key features of the database is that it contains unusually good information about students residing in the district that attend private, charter, and home schools. Unfortunately, we do not observe test scores for students outside of the district.

Table 3 shows descriptive statistics for the entire sample used in this study as well as two important sub-samples that we also consider in estimation. We only consider 
binding lotteries in this research because treatment and comparison groups are required for the experimental design. In total, over the time frame of the data, there are 203 binding lotteries with 1,396 students lotteried-in and 981 students lotteried-out.

Before we implement the estimators, we check whether the lotteries are balanced on student observables to ensure a clean experimental design. While assignment within lotteries may be random, participation in a lottery is not. To make use of within-lottery randomness and not the between-lottery non-randomness, we perform a check for balance by running a lottery-fixed effect regression for each observable characteristic as a dependent variable with acceptance as the only independent variable other than the fixed effects. Separate lotteries are held by race, so race is left out of the balance analysis. We test every other observable student characteristic in the data set. Following Cullen et al. (2006) we use equation (41) to determine whether the lottery is balanced:

$$
X_{i}=\beta_{1} W_{i}+\sum_{j=1}^{J} I_{i j} \beta_{2 j}+v_{i}
$$

where $X_{i}$ is the observable characteristic of interest, $W_{i}$ is a dummy equal to one if student $i$ wins lottery $j, I_{i j}$ is an indicator variable if $i$ participated in lottery $j$, and $v_{i}$ is the error term. ${ }^{17}$ We estimate a separate regression for each observable. The coefficient $\beta_{1}$ determines the fairness of the lottery system. If we cannot reject the null hypothesis that it is equal to zero, then acceptance into a magnet is not determined by the value of that particular student observable.

The first column of Table 4 shows the results when all students in all binding lotteries are included in the regressions. $\beta_{1}$ is not significant for any tested variable at $10 \%$. The second and third columns consider the two sub-samples of interest. The second column includes all students in elementary school while the third column

\footnotetext{
${ }^{17}$ Alternatively we could use multivariate Behrens-Fisher type test statistics which require less restrictive assumptions. See, for example, Kim (1992).
} 
Table 4: Balance of Prior Student Characteristics Between Lottery Winners and Losers

\begin{tabular}{|l|l|l|l|}
\hline Variable & Entire Sample & $\begin{array}{l}\text { Elementary School } \\
\text { Applicants Only }\end{array}$ & $\begin{array}{l}\text { High School } \\
\text { Applicants Only }\end{array}$ \\
\hline Math Test Score & $21.19(15.04)[1049]$ & - & $31.76^{*}(19.24)^{*}[627]^{*}$ \\
\hline Reading Test Score & $28.37(17.99)[1048]$ & - & $22.26(26.13)[627]$ \\
\hline Sex & $0.0034(0.0267)[2161]$ & $0.0245(0.0389)[871]$ & $-0.0087(0.0472)[820]$ \\
\hline Race & $0.0017(0.0047)[2268]$ & $0.0058(0.0073)[912]$ & $0.0009(0.0083)[861]$ \\
\hline FRL & $0.0036(0.0234)[2161]$ & $0.0161(0.0328)[871]$ & $0.0275(0.0433)[820]$ \\
\hline Poverty & $-0.0051(0.0069)[2162]$ & $-0.0024(0.0093)[872]$ & $-0.0195(0.0134)[820]$ \\
\hline Education & $0.0038(0.0078)[2162]$ & $0.0095(0.0126)[872]$ & $-0.0007(0.0123)[820]$ \\
\hline
\end{tabular}

*Significant at $10 \%$

focuses on high school students. The last group of students is similar to the one chosen by Cullen et al. (2006). This particular subset of students showed low overall attrition and, perhaps more importantly, similar attrition rates for lottery winners and losers. We find that the estimate of $\beta_{1}$ is rarely significant, even at the $10 \%$ level. This supports our earlier assumption about the orthogonality of $W$ and $X$.

The results shown in Table 4 support the notion that the lotteries are fair, creating separate winner and loser groups that are similar in all known characteristics. Any differences between winners and losers are small and statistically insignificant. Therefore, this randomized design theoretically also balances the two groups on unobservable characteristics such as motivation and parental involvement. This holds for the overall population in binding lotteries and for smaller sub-samples that were tested. 


\section{Empirical Results}

Since the lotteries appear to be balanced, our research is valid and we implement our new estimators. The results are summarized in Table 5. We report estimates and estimated standard errors of the fraction of households in each latent class as well as some relevant household characteristics. The characteristics include race, gender, free or reduced lunch, poverty, and college education. Note that the last two measures are based on neighborhood characteristics as reported by the U.S. Census. We report estimates for the full sample of all students as well for the subsample of students that applied to a magnet program that was associated with an elementary school. ${ }^{18}$

Table 5 reveals some interesting new insights into the application process and the decision making process of households. We find that the probability of winning the lottery is 0.65 if we average over all programs. The fraction of households that we estimate to be at risk is substantial and consist of 19 percent of the underlying population. Among the 73 percent of households that are not at risk, the vast majority will attend the magnet program if they win they lottery. There are only 9 percent of households that will leave the district regardless of the outcome of the lottery. Overall, these results suggest that most households consider the magnet programs desirable. Our estimates imply that approximately 250 households - 12 percent of the underlying sample - decided to stay in the district because they won the magnet lottery.

Equally interesting are the characteristics of the households that are at risk. For each characteristic, the differences across household types (at risk, leavers, stayers)

\footnotetext{
${ }^{18}$ We illustrate our approach by combining data across similar magnet programs. Ideally we would like to apply our approach to individual programs, but the sample sizes are too small to precisely estimate causal effects by program for almost all programs, except perhaps the five largest programs. The largest program contributes 491 observations to our sample.
} 
Table 5: Empirical Results

\begin{tabular}{|c|c|c|c|c|c|}
\hline & & \multicolumn{2}{|c|}{ All Schools } & \multicolumn{2}{|c|}{ Elementary Schools } \\
\hline & & Coefficient & Std. Error & Coefficient & Std. Error \\
\hline \multirow{5}{*}{ Fraction } & Win & 0.65 & 0.01 & 0.56 & 0.02 \\
\hline & At Risk & 0.19 & 0.02 & 0.22 & 0.03 \\
\hline & Stay Attend Magnet & 0.64 & 0.02 & 0.59 & 0.03 \\
\hline & Stay-Non Magnet & 0.09 & 0.01 & 0.07 & 0.01 \\
\hline & Leave & 0.09 & 0.01 & 0.12 & 0.01 \\
\hline \multirow{4}{*}{ Black } & At Risk & 0.58 & 0.05 & 0.46 & 0.06 \\
\hline & Stay-Magnet & 0.81 & 0.01 & 0.69 & 0.03 \\
\hline & Stay-Non Magnet & 0.67 & 0.04 & 0.31 & 0.08 \\
\hline & Leave & 0.43 & 0.04 & 0.28 & 0.06 \\
\hline \multirow{4}{*}{ Female } & At Risk & 0.55 & 0.05 & 0.60 & 0.07 \\
\hline & Stay-Magnet & 0.52 & 0.02 & 0.50 & 0.03 \\
\hline & Stay-Non Magnet & 0.53 & 0.05 & 0.52 & 0.09 \\
\hline & Leave & 0.37 & 0.04 & 0.39 & 0.06 \\
\hline \multirow{4}{*}{ FRL } & At Risk & 0.16 & 0.04 & 0.18 & 0.05 \\
\hline & Stay-Magnet & 0.43 & 0.02 & 0.46 & 0.03 \\
\hline & Stay-Non Magnet & 0.26 & 0.04 & 0.29 & 0.08 \\
\hline & Leave & 0.08 & 0.02 & 0.05 & 0.03 \\
\hline \multirow{4}{*}{ Poverty } & At Risk & 0.21 & 0.01 & 0.20 & 0.02 \\
\hline & Stay-Magnet & 0.24 & 0.01 & 0.24 & 0.01 \\
\hline & Stay-Non Magnet & 0.23 & 0.01 & 0.18 & 0.02 \\
\hline & Leave & 0.15 & 0.01 & 0.12 & 0.01 \\
\hline
\end{tabular}


Table 5: Empirical Results (cont.)

\begin{tabular}{|c|c|c|c|c|c|}
\hline & & \multicolumn{2}{|c|}{ All Schools } & \multicolumn{2}{c|}{ Elementary Schools } \\
\hline \multirow{3}{*}{ College } & Coefficient & Std. Error & Coefficient & Std. Error \\
\cline { 2 - 6 } & At Risk & 0.34 & 0.02 & 0.42 & 0.04 \\
& Stay-Magnet & 0.27 & 0.01 & 0.30 & 0.01 \\
& Stay-Non Magnet & 0.32 & 0.02 & 0.41 & 0.04 \\
& Leave & 0.38 & 0.02 & 0.40 & 0.04 \\
\hline \multirow{2}{*}{$\#$ Observations } & \multicolumn{2}{|c|}{2268} & \multicolumn{3}{c}{905} \\
\hline
\end{tabular}

are statistically significant. We find that these households are on average less likely to be African American and on free or reduced lunch programs than households that are stayers. Moreover, they come from more affluent and better educated neighborhoods. ${ }^{19}$ We thus conclude that magnet programs are effective devices for the school district to retain more affluent households. Not surprisingly, the group that are leavers are the most affluent group. These households may just apply to the magnet programs as a back-up option in case their students should unexpectedly not be admitted to an independent, charter, or parochial school. ${ }^{20}$

Table 5 also provides estimates when we restrict attention to households that apply to programs that provide education for children in elementary school. These programs are slightly more competitive as can be seen from the lower probability of winning (0.56 versus 0.65). Moreover, these programs attract a more educated

\footnotetext{
${ }^{19}$ Note that the differences in household characteristics are statistically significant from zero at all conventional levels.

${ }^{20}$ It could also be that these households left the district because of job transfers or other issues unrelated to schools.
} 
clientele. The fraction of African American families is also lower in this subsample. Not surprisingly, we find that the fraction of at risk families and the fraction of leavers is also higher in this sample. This finding highlights the fact the market for elementary school education is more competitive than the market for high school education.

Table 6: Ability Sorting

\begin{tabular}{|c|c|c|c|}
\hline & & \multicolumn{2}{|c|}{ High Schools } \\
\hline & & Coefficient & Std. Error \\
\hline \multirow{5}{*}{ Fraction } & Win & 0.86 & 0.01 \\
\hline & At Risk & 0.06 & 0.04 \\
\hline & Stay Attend Magnet & 0.83 & 0.04 \\
\hline & Stay-Non Magnet & 0.06 & 0.01 \\
\hline & Leave & 0.05 & 0.01 \\
\hline \multirow{4}{*}{ Math } & At Risk & 1399 & 169 \\
\hline & Stay-Magnet & 1261 & 13 \\
\hline & Stay-Non Magnet & 1262 & 45 \\
\hline & Leave & 1347 & 45 \\
\hline \multirow{4}{*}{ Reading } & At Risk & 1380 & 165 \\
\hline & Stay-Magnet & 1299 & 16 \\
\hline & Stay-Non Magnet & 1238 & 42 \\
\hline & Leave & 1413 & 56 \\
\hline \multicolumn{2}{|c|}{ \# Observations } & \multicolumn{2}{|c|}{530} \\
\hline
\end{tabular}

Finally, we consider the results for high school applicants. This sub-sample is interesting since we observe test scores for all students in these subsample. We can thus analyze sorting based on ability measured by prior test scores. We implement our GMM estimator using the full set of observed characteristics. In Table 6. we 
only report the results that pertain to attraction and retention as well as to sorting by ability. ${ }^{21}$

Results are reported in Table 6 . We find that the fraction of households that are at risk and leavers are much smaller than in the full sample. Overall Table 6 provides some evidence in favor of ability sorting. Households that are considered to be at risk have on average children with higher math and reading test scores. Households that stay in the district regardless of the outcome of the lottery have the lower test scores. We thus conclude that magnet program retain higher ability students who would leave the district in the absence of these programs.

\section{Conclusions}

We have considered a research design in which program participation is only partially determined by randomization. These designs arise when randomization occurs at the application stage and potential participants that are randomized into the program can always opt out before the program begins. These designs are commonly used to determine access to oversubscribed program offered by public school systems. We have developed a new empirical method which classifies potential participants in to stayers, leavers, and those that are at risk. The last group of individuals are most interesting form a policy perspective since the decision to participate crucially depends on the outcome of the lottery. We have shown that the parameters that characterize the causal effects are identified and can be estimated using a GMM estimator. Commonly applied IV and OLS estimators partially identify key components of our framework.

We have applied our new methods to study the effectiveness of magnet program in attracting and retaining students and households in a mid-sized urban school district.

\footnotetext{
${ }^{21}$ The full set of results are available upon request from the authors.
} 
Our findings suggest that magnet programs are useful tools that help the district to attract and retain students from middle class backgrounds. These households have many options outside the public school system. It is considerably more difficult to study the impact of these programs on achievement because of attrition and selection. Some households that do not win the lottery decide to leave the district and pursue other school options for their children. These households have very different observable characteristics then the households that stay behind. It is therefore plausible to assume that households also differ in unobserved characteristics. As a consequence, our experimental design allows us to point identify and estimate the effects associated with retention and attraction of students. For other treatment effects we can construct informative bounds. 


\section{References}

Abadie, A. and Imbens, G. (2006). Large Sample Properties of Matching Estimators for Average Treatment Effects. Econometrica, 74 (1), 235-67.

Angrist, J. (1990). Lifetime Earnings and the Vietnam Era Draft Lottery: Evidence from Social Security Administrative Records. American Economic Review, 80, 313-36.

Angrist, J., Bettinger, E., Bloom, E., King, E., and Kremer, M. (2002). Vouchers for Private Schooling in Colombia: Evidence from a Randomized Natural Experiment. American Economic Review, 92, 1535-58.

Angrist, J. and Imbens, G. (1994). Identification and Estimation of Local Average Treatment Effects. Econometrica, 62 (2), 467-79.

Angrist, J., Imbens, G., and Rubin, D. (1996). Identification of Causal Effects Using Instrumental Variables. Journal of the American Statistical Association, 91, 444-56.

Ballou, D., Goldring, E., and Liu, K. (2006). Magnet Schools and Student Achievement. Working Paper.

Bjorklund, A. and Moffitt, R. (1987). The Estimation of Wage and Welfare Gains in Self-Selection Models. Review of Economics and Statistics, 69, 42-49.

Cullen, J., Jacob, B., and Levitt, S. (2006). The Effect of School Choice on Student Outcomes: Evidence From Randomized Lotteries. Econometrica, $74(5), 1191-230$.

Durbin, J. (1954). Errors in Variables. Review of the International Statistical Institute, 22, 23-32.

Fisher, R. (1935). Design of Experiments. Hafner. New York.

Hansen, L. P. (1982). Large Sample Properties of Generalized Method of Moments Estimators. Econometrica, 50 (4), 1029-1053.

Hastings, J., Kane, T., and Staiger, D. (2006). Paternal Preferences and School Competition: Evidence from a Public School Choice Program. Working Paper.

Heckman, J. (1978). Dummy Endogenous Variables in a Simultaneous Equation System. Econometrica, 46, 931-960.

Heckman, J. (1979). Sample Selection Bias as a Specification Error. Econometrica, 47 (1), 153-161. 
Heckman, J. and Honore, B. (1990). The Empirical Content of the Roy Model. Econometrica, 58 (5), 1121-49.

Heckman, J., Ichimura, H., and Todd, P. (1997). Matching As An Econometric Evaluation Estimator: Evidence from Evaluating a Job Training Program. Review of Economic Studies, 64 (4).

Heckman, J. and Robb, R. (1985). Alternative Methods for Evaluating the Impact of Interventions. In Longitudinal Analysis of Labor Market Data. Cambridge University Press.

Heckman, J. and Vytlacil, E. (2005). Structural Equations, Treatment Effects and Econometric Policy Evaluation. Econometrica, 73.

Heckman, J. and Vytlacil, E. (2007). Econometric Evaluation of Social Programs. In Handbook of Econometrics 6b. Elsevier North Holland.

Hoxby, C. and Rockoff, J. (2004). The Impact of Charter Schools on Student Achievement. Working Paper.

Kim, S. (1992). A Practical Solution to the Multivariate Behrens-Fisher Problem. Biometrica, 79, $171-6$.

Lee, L. (1979). Identification and Estimation in Binary Choice Models with Limited (Censored) Dependent Variables. Econometrica, 47, 977-996.

Maddala, G. (1983). Limited Dependent and Qualitative Response Variables in Econometrics. Cambridge University Press.

Moffitt, R. (2008). Estimating Marginal Treatment Effects in Heterogeneous Populations. Working Paper.

Quandt, R. (1972). A New Approach to Estimating Switching Regression Models. Journal of the American Statistical Association, 67, 306-310.

Rosenbaum, P. and Rubin, D. (1983). The central role of the propensity score in observational studies for causal effects. Biometrica, 70, 41-55.

Rouse, C. (1998). Private School Vouchers and Student Achievement: An Evaluation of the Milwaukee Parental Choice Program. Quarterly Journal of Economics, 113, 553-602.

Rubin, D. (1974). Estimating Causal Effects of Treatment in Randomized and Nonrandomized Studies. Journal of Educational Psychology, 66, 688-701.

Rubin, D. (1978). Bayesian Inference For Causal Effects. Annals of Statistics, 6, 34-58. 